\title{
A Study of the Influence of Operating Conditions on the Degradation of the Structure of Steel 14MoV63
}

Oleg A. Masanskii, Aleksander M. Tokmin and Vladimir S. Kasakov* Siberian Federal University 79 Svobodny, Krasnoyarsk, 660041, Russia

Received 25.03.2019, received in revised form 22.05.2019, accepted 01.06.2019

The results of the study of the microstructure and properties of the manufactured pipe fragments of steel pipe lines 14 MoV63 are given. The deterioration of the structure of the steel during operation and changes in mechanical properties are considered.

Keywords: structure degradation, spheroidization, intercrystalline corrosion, steam pipeline.

Citation: Masanskii O.A., Tokmin A.M., Kasakov V.S. A study of the influence of operating conditions on the degradation of the structure of steel 14MoV63, J. Sib. Fed. Univ. Eng. technol., 2019, 12(4), 427-432. DOI: 10.17516/1999-494X-0148.

\section{Исследование влияния условий эксплуатации}

на деградацию структуры стали 12Х1МФ

\section{О.А. Масанский, А.М. Токмин, В.С. Казаков \\ Сибирский федеральный университет Россия, 660041, Красноярск, пр. Свободный, 79}

Приведены результаты исследования микроструктуры и свойств образиов, выполненных из фрагментов труб паропроводов из стали 12 Х1МФ. Рассмотрена деградаиия структуры стали в проиессе эксплуатации и изменения механических свойств.

Ключевые слова: деградация структуры, сфероидизащия, межкристаллитная коррозия, паропровод.

(C) Siberian Federal University. All rights reserved

This work is licensed under a Creative Commons Attribution-NonCommercial 4.0 International License (CC BY-NC 4.0)

* Corresponding author E-mail address: pi775@yandex.ru, vskazakov@yandex.ru 


\section{Введение}

Эксплуатация котельного оборудования тепловых электростанций происходит под воздействием механических и температурных напряжений, статических и динамических нагрузок, коррозионно-активных сред, компенсационных нагрузок и т.п. Результатом такого воздействия являются изменения структурно-фазового состава, повреждения поверхностей нагрева и внутренних частей, обусловленные протеканием коррозионно-эрозийных процессов.

Деградация структуры, возникновение напряжений, коррозионных язв и другого в металле элементов такого оборудования приводит к возникновению рисков аварийных ситуаций, неплановых остановов, отказа оборудования и т.п. Поэтому комплексный подход, включающий изучение многофакторного воздействия на изменение структуры и возникновение повреждений поверхностей нагрева металла котельного оборудования для проведения анализа причин повреждений с целью определения ресурса работоспособности, с применением современных методик имеет особую актуальность.

\section{Влияние условий эксплуатации металла котельного оборудования на повреждаемость и долговечность}

Металл паропроводов, пароперегревателей, коллекторов и других элементов котла ТЭС, эксплуатация которых происходит при температурах пара выше $500{ }^{\circ} \mathrm{C}$, с течением времени претерпевает фазовые и структурные превращения и, как следствие, изменение механических свойств. В результате длительного воздействия высоких температур и давлений непрерывно протекают процессы, приводящие как к упрочнению, так и к разупрочнению стали.

Изучение процессов, протекающих в металле в результате воздействия высоких температур в течение длительного времени, имеет большое значение для обеспечения и повышения эксплуатационной надежности котельного оборудования.

Все структурные изменения, происходящие в перлитных сталях, к которым относятся стали 16М, 12МХ, 15ХМ и 12Х1МФ, в процессе их эксплуатации, можно свести к следующим основным моментам: изменения в феррите и перлите и изменения по границам зерен $[1,2]$.

\section{Исследование микроструктуры и свойств}

Наши исследования позволяют определить влияние длительного воздействия температуры и давления на деградацию микроструктуры на образцах, вырезанных из паропроводов, изготовленных из стали 12Х1МФ. Исходная структура стали 12Х1МФ состоит из феррита пластинчатого перлита (рис. 1a). На начальном этапе процесса эксплуатации наблюдается выделение дисперсных фаз в твердом растворе и сфероидизация цементита в перлите (рис. 1б). Изменения в структуре металла, непрерывно протекающие в течение длительного времени, оказывают влияние на комплекс механических свойств: выделение карбидной фазы в твердом растворе приводит к повышению твердости и прочности за счет эффекта дисперсионного твердения. В табл. 1 приведены результаты изменения микротвердости структурных составляющих стали до и после эксплуатации.

Повышение твердости металла характерно на начальной стадии процесса. Дальнейшая эксплуатация приводит к протеканию сфероидизации и, как следствие, снижению твердости. 


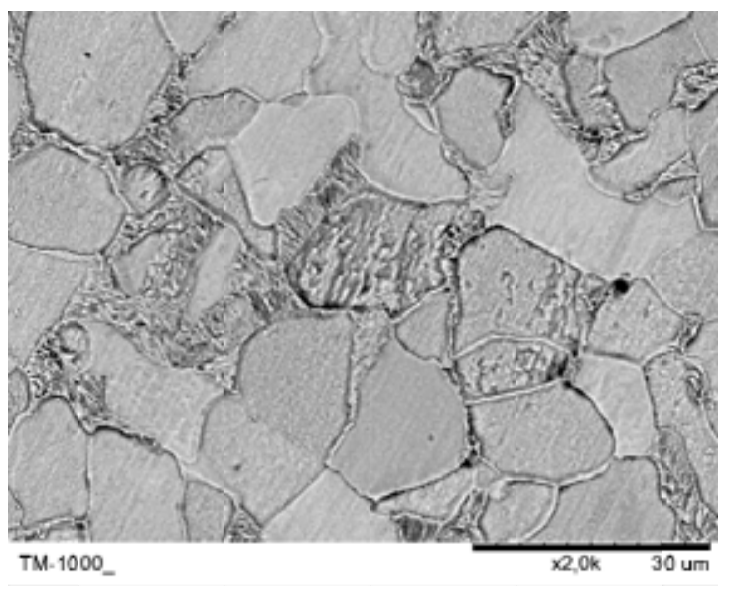

$a$

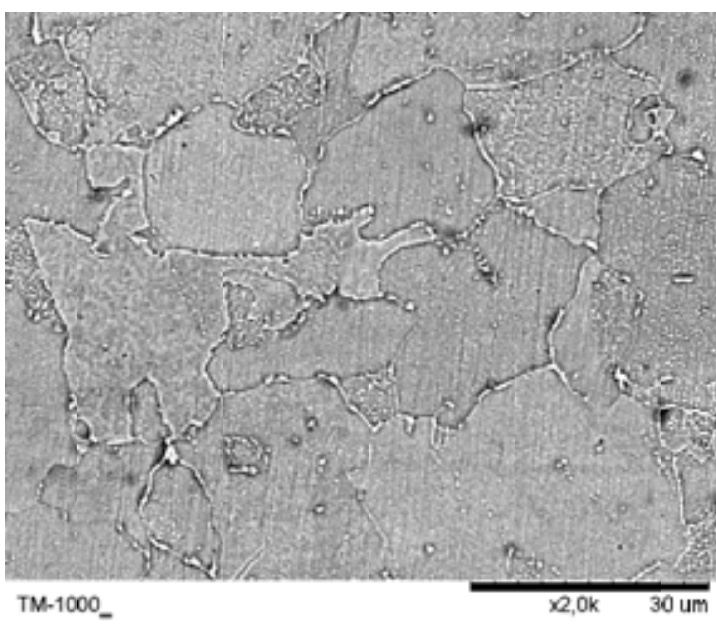

6

Рис. 1. Микроструктура стали $12 \mathrm{X} 1 \mathrm{MФ,} \times 2000: a$ - исходная структура; $\sigma$ - после эксплуатации

Fig. 1. Microstructure of steel $14 \mathrm{MoV} 63, \times 2000: a-$ source structure; $\sigma-$ after operation

Таблица 1. Микротвердость (МПа) структурных составляющих стали 12Х1МФ

Table 1. Microhardness (MPa) structural components of steel 14MoV63

\begin{tabular}{|c|c|c|c|}
\hline \multicolumn{2}{|c|}{ До эксплуатации } & \multicolumn{2}{c|}{ После эксплуатации } \\
\hline Феррит & перлит & феррит & перлит \\
\hline 650 & 1750 & 1144 & 2450 \\
\hline
\end{tabular}

Увеличение размеров карбидной фазы ускоряет процессы ползучести и приводит к снижению срока эксплуатации.

Отличительной особенностью исследованных паропроводов со сроком эксплуатации более 100 тыс. ч является наличие структуры, состоящей из феррита и вторичной фазы, расположенной в виде непрерывной цепочки по границам зерен феррита (рис. 2).

$$
-429-
$$




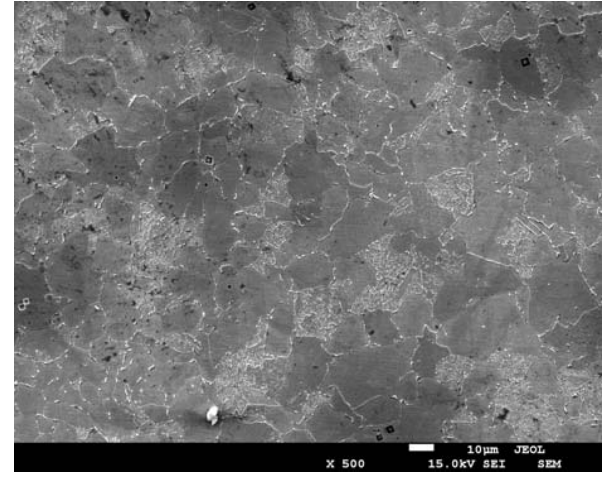

$a$

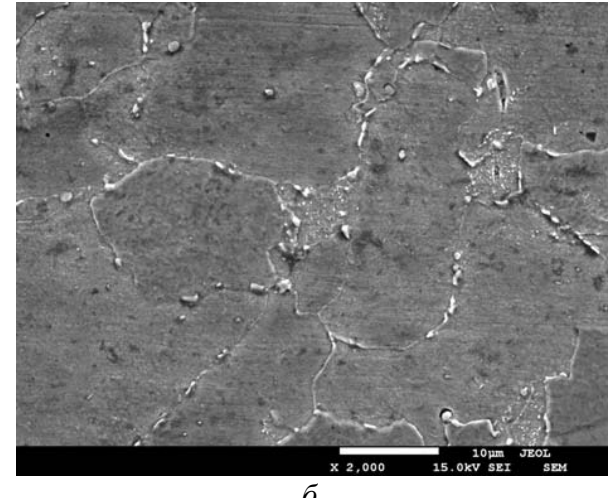

6

Рис. 2. Микроструктура стали $12 X 1 \mathrm{MФ,} \mathrm{наблюдается} \mathrm{выделение} \mathrm{вторичной} \mathrm{фазы} \mathrm{по} \mathrm{границам} \mathrm{зерен:}$ $a-\times 500 ; \sigma-\times 2000$

Fig. 2. Microstructure of steel $14 \mathrm{MoV} 63$, there is a release of the secondary phase along the grain boundaries: $a-\times 500 ; \sigma-\times 2000$

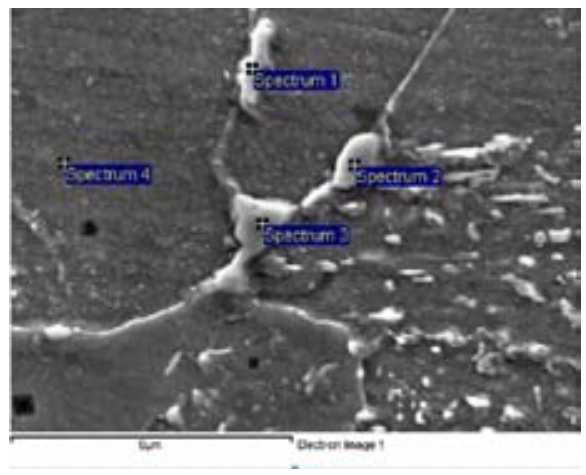

Рис. 3. Энергодисперсионный анализ

Fig. 3. Energy dispersive analysis

Проведенный энергодисперсионный анализ отдельных фаз (рис. 3) показывает (табл. 2) большое содержание углерода и легирующих карбидообразующих элементов (хром, ванадий, молибден) во вторичной фазе (спектры $1,2,3)$ и их практическое отсутствие в спектре 4 , соответствующем твердому раствору. Полученные результаты позволяют сделать вывод, что по границам зерен происходит выделение карбидной фазы. Выделение карбидной фазы обусловлено протеканием ускоренной диффузии легирующих элементов к границам зерен под влиянием высоких температур.

Образование карбидной фазы приводит к обеднению твердого раствора (феррита) легирующими элементами, что вызывает снижение прочности и, как следствие, понижение предела ползучести.

\section{Коррозия стали}

Проведенный структурно-фазовый анализ наружного коррозионного слоя (окалины), образованного в результате воздействия топочных газов при сгорании угольной пыли, показал, 
Таблица 2. Результаты энергодисперсионного анализа

Table 2. The results of energy dispersive analysis

\begin{tabular}{|c|c|c|c|c|c|}
\hline \multirow{2}{*}{ № } & \multicolumn{5}{|c|}{ Содержание, \% } \\
\cline { 2 - 6 } & $\mathrm{C}$ & $\mathrm{Cr}$ & $\mathrm{V}$ & Fe & Мо \\
\hline Spectrum 1 & 26.85 & 3.31 & 1.47 & 65.05 & 3.32 \\
\hline Spectrum 2 & 31.33 & 9.12 & 5.20 & 50.97 & 3.39 \\
\hline Spectrum 3 & 34.80 & 8.97 & 4.81 & 48.32 & 3.11 \\
\hline Spectrum 4 & - & 1.20 & - & 98.80 & - \\
\hline
\end{tabular}
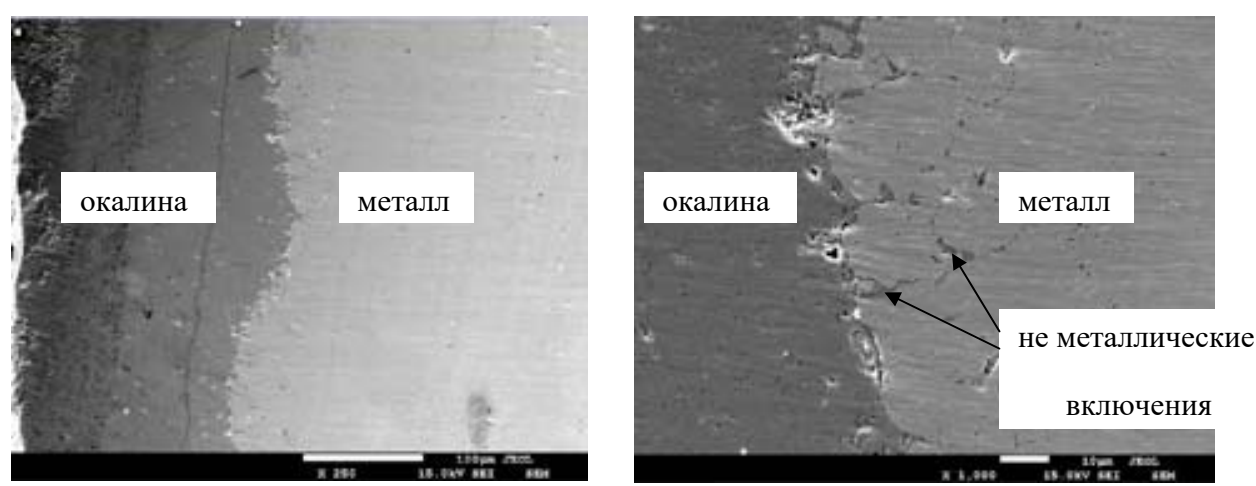

Рис. 4. Газовая коррозия: $a-\times 250 ; \sigma \times 1000$

Fig. 4. Gas corrosion: $a-\times 250 ; \sigma \times 1000$

Таблица 3. Результаты энергодисперсионного анализа

Table 3. The results of energy dispersive analysis

\begin{tabular}{|c|c|c|c|}
\hline \multirow{2}{*}{ № } & \multicolumn{3}{|c|}{ Содержание, \% } \\
\cline { 2 - 4 } & O & $\mathrm{Cr}$ & Fe \\
\hline Spectrum 1 & 25.98 & - & 74.02 \\
\hline Spectrum 2 & 25.28 & 2.06 & 72.67 \\
\hline Spectrum 3 & - & 0.91 & 99.09 \\
\hline
\end{tabular}

что слой представляет собой гетерогенную систему, состоящую из нескольких зон (рис. $4 a$ ). Образование коррозионного слоя влечет за собой обеднение твердого раствора легирующими элементами и снижение его коррозионной стойкости. Снижению коррозионной стойкости также способствует формирующаяся по границам зерен карбидная фаза. Карбиды и феррит обладают разностью потенциалов, которая при наличии электролита приводит к образованию гальванических пар и, как следствие, протеканию электрохимической коррозии. Проведенные на нетравленых образцах металлографические исследования (рис. 4) показывают наличие неметаллических включений по границам зерен.

Энергодисперсионный анализ точечных спектров (рис. 5, табл. 3) выявляет большое содержание кислорода в спектрах 1 и 2 и его отсутствие в 3-м спектре. 


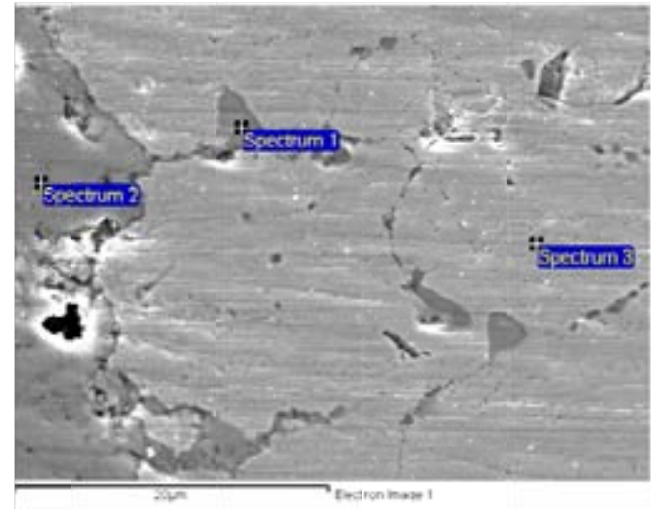

Рис. 5. Энергодисперсионный анализ

Fig. 5. Energy dispersive analysis

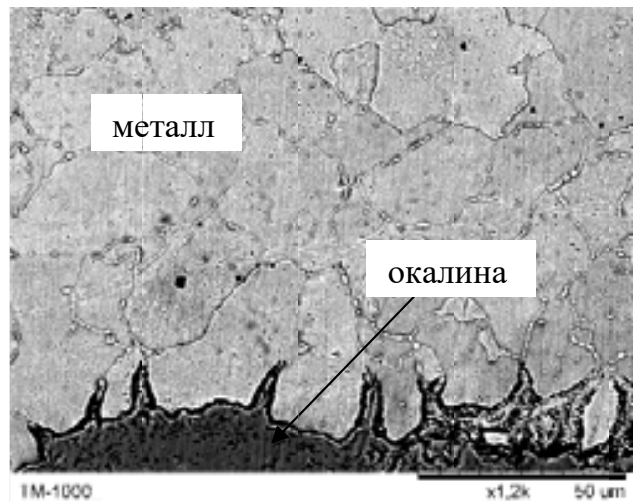

Рис. 6. Межкристаллитная коррозия, $\times 1200$

Fig. 6. Intergranular corrosion, $\times 1200$

Наличие кислорода в 1 и 2 спектрах позволяет сделать вывод, что образующиеся неметаллические включения являются оксидами железа и свидетельствуют о протекании коррозионных процессов.

Металлографические исследования, проведенные на травленых образцах, показывают, что образование коррозионных язв происходит по границам зерна феррита и носит межкристаллитный характер (рис. 6).

\section{Выводы}

Проведенные исследования деградации структуры стали 12Х1МФ в процессе длительной высокотемпературной эксплуатации показывают протекание фазовых и структурных превращений на различных сроках эксплуатации, приводящих к сфероидизации карбидной фазы и обеднению твердого раствора легирующими элементами, что вызывает значительное снижение прочностных характеристик. В результате воздействия атмосферы топочных газов на наружную поверхность трубы происходят коррозионные процессы, влекущие за собой межкристаллитную коррозию.

\section{Список литературы}

[1] Бугай Н.В., Шкляров М.И. Неразрушающий контроль металла теплоэнергетических установок. Москва: Энергия, 1978. 120 с. [Bugay N.V., Shklyarov M.I. Nondestructive control of metal of heat and power plants. Moscow: Energy, 1978. 120 p. (in Russian)].

[2] Баландина М.Ю. Влияние структурно-механической неоднородности на повреждаемость и долговременную прочность металла высокотемпературного оборудования ТЭС. Автореф. ... канд. техн. наук. СПб., 2008 [Balandina M.Yu. The effect of structural-mechanical heterogeneity on the damageability and long-term strength of the metal of high-temperature equipment of thermal power plants. Abstract ... candidate of technical sciences. St. Petersburg, 2008 (in Russian)]. 